\title{
SB 389
}

\section{. R55}

Copy 1

BROTILR JUNATHAN゙ SEKIES - NO. :
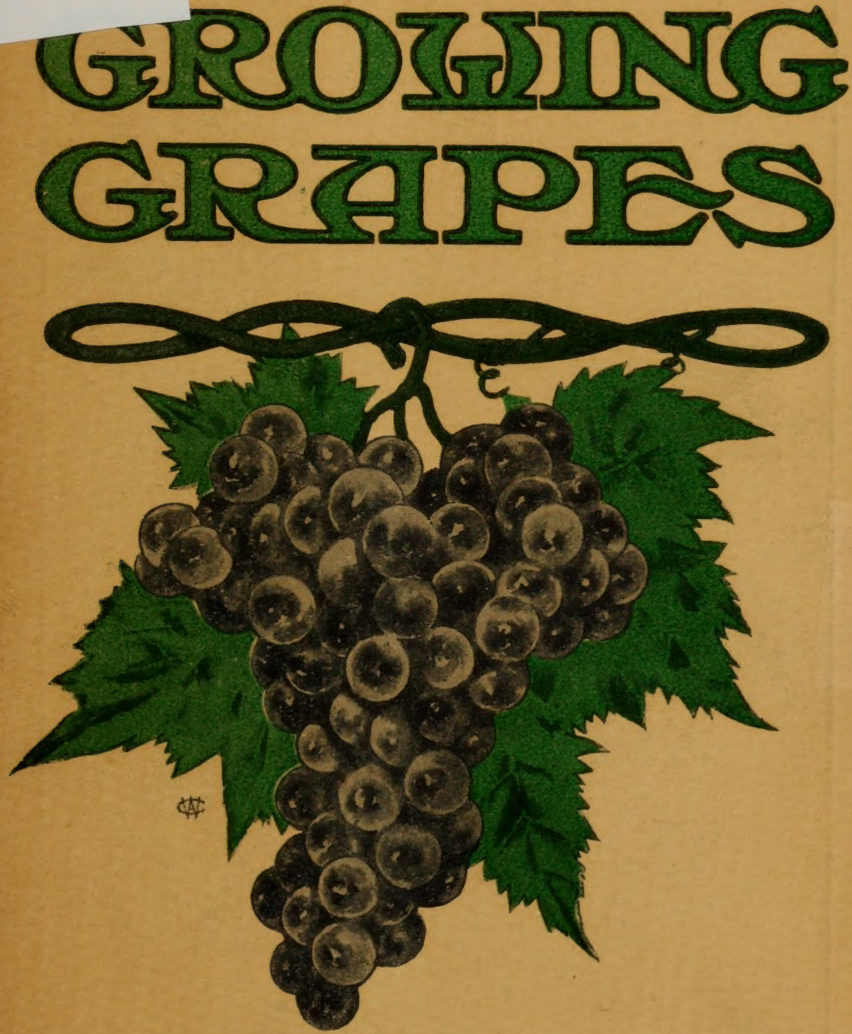

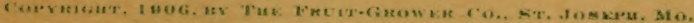




\section{"Bro.Jonathan' Series of Fruit Books}

Copyrighted and published exclusively by The Fruit-Grower Company, Saint Joseph, Missouri.

This is a series of booklets published by The Fruit-Grower Co., St. Joseph, Mo., on different phases of fruit culture, which are intended to help those engaged in the pursuit of horticulture. All books are lllustrated.

No. 1- "Propagating Trees and Plants."-Describes the process of budding, grafting, layering, etc. It is by Prof. W. L. Howard of the University of Missouri, with protographs by E. H. Favor, of the same institution.

No. 2- "A Treatise on Spraying."-By Prof. J. M. Stedman, entomologist of the Missouri Experiment Station. Many of the most destructive insects are shown, with full directions for combating them:

No. 3- "How to Grow Strawberries."-By Dr. J. C. Whitten, professor of horticulture of the University of Missouri. It treats of growing Strawberries as a commercial crop or for home use.

No. 4-"The Home Garden."-By Prof. Howard and Mr. Favor. It tells how to make hotbeds, coldframes, etc,; how to handle them to the best advantage. The more common garden vegetables are discussed, together with some which are too often neglected.

No. 5-"Packing and Marketing Fruits."-By Prof. F. A. Waugh, of Massachusetts Agricultural College. This book tells about the correct times for picking different fruits, describes different packages used in which to market them.

No. 6-"A Book About Bush Fruits."-By Prof. A. T. Erwin of Iowa Agricultural College. Treats of blackberries, raspberries, etc., with methods of culture; also gives recipas for canning and preserving.

No. 7- "Growing Grapes."-By E. H. Riehl, Alton, Ill. Mr. Riehl is a successful commercial grower, and discusses varieties, modes of training, etc.

No. 8- "Hints on Pruning."-By Dr. J. C. Whitten. The pruning of different kinds of fruit trees and plants is discussed, with reasons for the methods recommended.

No. 9- "Apple Culture, with a Chapter on Pears."-By Dr. J. C. Whitten. This is intended to be a booklet for the practical man who wants to know how to get some good from his orchard.

No. 10-"Success With Stone Fruits."-By Prof, F. A. Waugh. The different stone fruits are treated, with lists of best varieties of each. Methods of planting, pruning, etc., are discussed for each class.

These Booklets Will Be Sent Postpaid for

\section{5c Each or Five for One Dollar}




\section{G R OWIN G

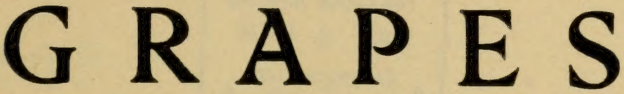

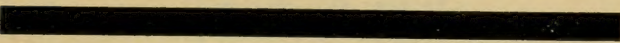

By Edlvin $H$ Riehl

President of the Alton (I11.) Horticultural Society; Manager Illinois State Experiment Station No. 8

PUBLISHED BY THE FRUIT-GROWER COMPATY 1906 SAINT JOSEPH, MISSOURI 


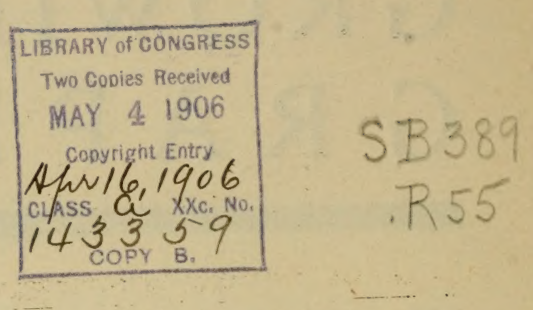




\section{Brother Jonathan}

Series

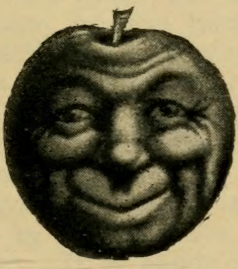

Booklet No. 7. 



\section{INTRODUCTORY.}

In the grape we have the ideal fruit for the masses. The apple is no doubt of more value commercially, but when we consider that the grape may be grown in thousands of homes where the apple cannot, we must regard the grape as the people's fruit. No matter how small the yard may be, whether in city, village or country, there is always room for a few grape vines, for nowhere does this fruit flourish better than when trained to dwellings, outbuildings or over arbors. In the shape of arbors it frequently furnishes shade which could not be had from trees, there being no room for the latter. The grape is one of the most delicious and wholesome fruits we have; it represents a good many shades of color and flavors, so that all persons may find among our long list of varieties, some that are to their liking.

No other fruit will thrive in so great a variety of soils as does the grape and varieties may be selected that will succeed in any climate where any other fruit can be grown. It is easily propagated, easily grown, bears early, lives much longer than the average fruit plant or tree and gives us a far greater amount of fruit annually, considering the space occupied, than any other fruit-bearing plant, tree or vine.

This little book, which is based on practical experience, is offered mainly for the benefit of amateurs, though it is to be hoped that all who read it will find among its pages suggestions that will be interesting and beneficial. 


\section{SOIL AND LOCATION.}

The grape is not particular as to soil, but gives good results in soils that are rocky, sandy, heavy clay, rich or poor, under conditions where other fruits would fail. This, however, does not mean that it is not important to select good soil for the vineyard and keep it so. The grape vine is a great feeder and responds freely and quickly when the right fertility is provided. A clay loam will, perhaps, give the best general results. While it is desirable to have the soil very rich for best results, it should be remembered that richness of soil has a tendency to encourage fung 1 , to which this fruit is especially subject.

The best location for a vineyard is well-drained land, sloping to the east or south, the object of such a slope being that the early morning sun quickly dries off the dew, which greatly lessens the danger of fungus injury. Steep hillsides are frequently used for growing grapes, and good crops are grown where nothing else could be profitably produced. In such cases terraces are made, wide enough so that a onehorse cultivator may be run on either side of the rows. It should not be understood frorn these suggestions that grapes can not be profitably grown on level land or even on low bottom land, for such is not the case. Grape vines thrive well on low and level land, but when such land is used it is necessary to spray promptly and continuously to prevent the fruit from rotting before it becomes ripe. New land from which timber has recently been cut should be used whenever practicable, as then the very best results may be expected. 


\section{PREPARATION OF THE SOIL.}

In some parts of Europe it is considered essential to dig trenches several teet wide and three feet deep, and fill up the excavation with gravel at the bottom, and the balance with rich prepared soil and thereon set the grape vines. Some of our German immigrants have practiced this method here and while the results were the very best, the work is too expensive to be practicable. In selecting soil for the grape see that it is as fertile naturally as practicable, with location in mind, and grow for at least two years previous to setting the vines, a crop of clover or cow peas, which crops should preferably be turned under in the fall when fully matured. Or, if a crop of clover may be had to plow under in June the soil should be worked down and cow peas sown, to be turned under in the fall. This will put so much needed humus in the soil as to admit of very early plowing in the spring. At this time the plow should be run as deeply as possible and the soil worked down fine and smooth. It should be remembered that vines properly set and cared for will live and give good results almost indefinitely, and too much pains cannot be taken in preparing the land. The soil should be especially rich at the time vines are planted, with the object of giving the vines a vigorous start and to hasten them to a bearing size. If manure is available it should be applied liberally to the land one or two years previous to the planting of the vineyard. Cow peas and clover, while they will not give the same amount of lasting plant food to the soil, have the advantage of freeing the soil partly of weeds, whereas manure, in most cases, contains a good deal of seed, thus introducing an addi- 
tional supply of weeds that are hard to subdue, no matter what crop is to be grown where hand labor is to be employed.

It may be said here, however, that the grape, under proper management, is one of the easiest crops to till and keep clean of weeds that we raise and the weed problem is therefore not a serious one, yet worthy of some consideration.

\section{SETTING THE VINES.}

Well-grown one-year-old vines are best for starting a vineyard; they will give better results, as a rule, than two-year-old vines, even though the latter are grown as they should be. The main objection to two-year vines, however, is that they frequently represent transplanted vines two or three years old, which, being unsold at the end of the season, are lined out in the nursery and carried over to the next season. Such vines are stunted and never give the best results.

The vines should be at hand at the time the soil is prepared by being well stirred and made fine to a considerable depth, which should be done at a time when soil is moist, care being taken not to work the ground when too wet. It is important to get the vines out as early in spring as the soil can be worked so it will crumble and break up nicely; the surface should be made smooth with drag or roller.

The distance to plant varies somewhat according to circumstances; from 6 by 8 feet to 8 by 12 feet. When soil is very rich and varieties vigorous, they should be set farther apart than otherwise and when rows are set eight feet apart every fifth row should be set farther to admit the manure wagon and 
sprayer. The holes should be dug large enough so that the roots may be spread out naturally, as neariy like they grew before as possible, and more than merely deep enough to admit roots to the proper depth, thus allowing for some good surface soil for the roots to rest upon. Before vines are set the tops should be cut back to about four eyes on the new growth and the roots cut back to ten inches in length. Numerous small rootlets are sent out to take the place of the comparatively few large ones cut off and the vines are thus considerably improved. As to the depth to set vines, we need not exercise the care necessary in setting the strawberry or other small plants; there is more danger of getting vines too shallow than there is in getting them too deep, as when set deep they throw out roots above those aiready formed and thus the vines are strengthened. It is best, however, to have at least two buds above ground.

As stated above, the vines should be placed at proper depth with roots spread naturally; good surface soil should then cover the roots and be tramped very firmly, there being no danger of getting them in the ground tou solid about the roots; near the surface the soil should be left loose.

In regard to the best time to set grape vines, early spring is best for the amateur, although it is possible to plant successfully any time when vines are dormant and soil in a condition to work well, excepting at the North, where it is advisable to plant altogether in spring. One disadvantage in fall planting is that frequently the weeds get a start in early spring before cultivation can be given, which makes the season's expense greater than it would be were the vines set in the spring. On the other hand, if we have the time to plant in the fall it is best not 
to put it off, as all have more than plenty of work to look after in busy springtime.

If many vines are received at a time from a.distance, care should be taken that the roots do not become dry before they are planted. If well packed they may be taken from the package in which they are sent as needed the roots being dipped in water just before planting. In case they are received some time before ground is ready for planting, the bundles should be broken and the vines heeled in thinly where the soil is mellow and dry enough.

\section{SUPPORT.}

There are various ways of supporting grape vines. They may be trained to buildings, over arbors, to single or double stakes or to trellises. The vineyardist who does not intend to cultivate both ways, should have the rows running north and south, except in cases where vineyards are on steep hillsides where the sun has a chance to shine over one row to another, the object being to have as much sunshine as possible strike both sides of vines during the course of each day.

For the amateur the single stake support is the best, because he is not so apt to overtax the vine. One vine to each root well cared for will give a good crop. Most amateurs will endeavor to cover a trellis completely with bearing wood and thereby exhaust the vine to such an extent as to render the vineyard unprofitable within the course of a few years. When vines are very vigorous, two stakes may be set, one on either side of the root. In cases where the slope is not too steep there is a great advantage in the stake system by being able to cultivate both ways and thus do away with a great 
deal of hand labor. It is a great advantage to select posts that last a long time in the ground, such as red cedar, black locust, mulberry, Osage Orange, catalpa speciosa, etc. Those who grow grapes on a large scale can well afford to plant any waste land to black locust, which grows most rapidly and lasts as well as any.

For the grower who thoroughly understands the grape vire and knows how to prune the different varieties, the trellis has some advantages, the main point in its favor being that it is not so expensive to keep in repair. Posts of the varieties mentioned above should be firmly set twelve feet apart. Two good No. 9 galvanized wires should be tightly stretched from post to post, well anchored at each end of row; one wire should be 6 feet from the ground, and one 18 inches lower. The vines should extend to the top wire with a bearing branch three to five feet in length extending each way, thus forming a letter $T$. In case of extraordinary vigor of vines, a little bearing wood may be left for the lower wire, but as a rule the lower wire should be used only to support the young wood for the next year's fruiting and for propagation.

The danger of overtaxing vines by leaving too much bearing wood is especially liable to occur when vines are trained to arbors. The idea seems to be that to furnish the most shade the wood should be entirely covered with dormant wood. In most cases if one-half the bearing wood were left, more and better shade would be had and the vines would not be cropped to death. It should be remembered that the more the old or dormant wood is cut back, the more vigorous will be the young growth, the latter furnishing by far the best shade.

The best way to support vines to the sides of 
buildings is by fastening them with strips of leather or tin.

When the stake system is used, one stake to a vine is ordinarily sufficient, though when vines are very vigorous two stakes may be used. Again it is sometimes a good plan to have one stake to support the crop and another for the young growth, which gives the fruit more air and sunshine than it could get if all were tied up to one stake. When stakes are used it is a good plan to have an extra supply of stakes on hand so that in case some stakes should be broken by storms, they may be promptly replaced. It should be remembered that if a vine loaded with fruit is allowed to lie on the ground for any length of time, not only the present crop is ruined, but the vine is injured to such in extent that it will not recover for several years. It may bear some fruit, but the fruit will ripen unevenly and be unmarketable. In buying stakes for the vineyard it should be remembered that a stake six inches through is worth four times as much in the long run as one three inches in diameter, for the reason that it is the heart of the tree that lasts best under ground.

\section{CULTIVATION.}

As with all other fruits, success or failure depends upon the amount of proper cultivation given. Although the grape is one of the easiest crops to cultivate, it is none the less important that the work should be thoroughly done. As soon as vines are planted the harrow should be run right over the vines and if a rain follows soon after it may be run a second or even a third time. This shallow cultivation is the very best that can be given and at the same time the cheapest. 
The greatest advantage of cultivation is not in killing the weeds, yet if we cultivate every time the weeds threaten to appear, which is after every rain or good shower, we are very apt to keep the surface well broken, as it should be at all times as nearly as possible.

Cultivation should begin in spring just as early os the ground is dry enough and the soil kept loose and mellow all through the growing season. The object in keeping the soil in such a condition is chiefly to enable it to receive and retain moisture. When vineyards are cultivated but one way and the rows hoed, care should be taken to leave the surface loose instead of simply scraping the weeds off and leaving the surface smooth as is in many cases done. When weeds get a start, as they will sometimes do, in cases of successive rains, the one-horse plow can be used to an advantage, but care should be taken not to run it too deep next to the vines. The best tool ordinarily is a one-horse cultivator or harrow.

\section{POLLENIZATION.}

Unlike the strawberry and some other fruits, the sex of the grape blossom is very hard to determine, and for this reason it is not safe to plant a variety by itself which we do not know is self-pollenizing. It is always well to plant with such varieties some well-known sort that we know will bear by itself, like Concord or Moore's Early. All varieties will produce some fruit, even though growing to themselves, but many varieties thus grown produce imperfect bunches which are not marketable and the weight of fruit is not there. Green Mountain is supposed to be one of the very best pollenproducing varieties in cultivation. 


\section{PRUNING.}

In no other fruit is the right sort of pruning so essential as with the grape; in fact, success or failure is based on that one point, even though all others have been observed. It is safe to say that more vineyards have been ruined by improper pruning than in any other way. The trouble with most growers is that they expect too much from their vines and leave too much bearing wood. In this way many vines have been made to crop themselves to death in the course of a few years that might have lived and produced good crops for fifty years if properly pruned. No fixed rule can be laid down for this work, as different varieties require different pruning. Moore's Early, for example, does best when small young canes not much larger than a lead pencil are left for fruiting, which is also the case with several other sorts. The vineyardist, therefore, should be a close observer of nature, he should study each variety and prune according to its needs. In most cases the strongest canes should be removed, and the medium sized ones left for fruiting. Most varieties bear best on young wood of the previous year's growth; it is therefore advisable to renew vines from year to year, much in the same way as we do raspberries and blackberries, only in case of the latter the old wood dies and with the grape we must have the nerve to cut it out and give the young wood a chance. When vines are trained to a trellis it is well with some varieties to leave the main vine permanent or at least for a few years, and each year renew the young canes that extend on the vines. Other varieties, like Norton's Virginia Seedling and Cynthiana, do best on old wood and need only be 
renewed say once in ten or fifteen years. In pruning the vines when dormant, not more than two or three buds should be left on each side branch of the main vine.

As to the proper time to prune, it may be done any time when the vine is thoroughly dormant, be it fall, winter or early spring. All tender varieties should be pruned in fall so they may be laid to the ground and protected. It is safe to say that more vines are ruined by not being pruned enough than by being pruned too severely. Cut a vine back severely and what fruit there is will be very choice and the vine left vioorous. Prune too sparingly and you will get poor fruit, frequently too poor for any use, and the vine will be greatly injured, if not ruined. The production of seed is the greatest tax on any tree, plant or vine-a point we should consider when we prune and thin fruit.

Summer pruning or pinching is beneficial when properly done, but is frequently abused. In consists, or should consist, of the ends of the young shoots bearing the fruit being pinched off with thumb and finger not closer than two leaves beyond the last bunch. This pinching should be done promptly, just as soon as the growth is long enough to permit of it being done and as the growth is frequently uneven, it is necessary to go over the vineyard several times. The object of such pruning is to balance up the vines, that is by pinching the first shoots that become long enough, it gives the weaker ones a chance to catch up and thus make the fruit ripen more evenly and perfectly. It also makes the bunches more compact, making many bunches marketable that otherwise would be too loose. This work is sometimes deferred until the wood hardens and then it is cut back carelessly with a knife. In 
such cases a great deal of harm is done and the vines would give far better results if they were not molested. To renew, two to three vigorous shoots should be allowed to grow up from the base or near the bottom of each vine, yearly, and the rest that may appear should be rubbed off soon after they start and those left should be tied up promptly as fast as they grow.

\section{THINNING}

Many varieties are too prolific. Close pruning will remedy the matter somewhat, but even then more bunches are formed than the vine can mature and the smaller ones should be taken off shortly after they are out of bloom. Woodruff is a variety that needs thinning perhaps more than any other. It is a good plan to do more or less thinning of all varieties by removing such small bunches as will not be fit for market, thus giving more energy io the remaining fruit. Grape vines often have double buds, from which two shoots grow; the weaker one of these should be pulled off while young and tender and other laterals that do not promise to give good fruit may also be removed, providing there are enough left to give the vine the amount of foliage it should have.

\section{ENEMIES OF THE GRAPE.}

Although the grape is one of the easiest fruits to grow, it is not without its share of pests. The first insect noticeable in a young vineyard is the leaf folder; the leaves are drawn together by webs and beneath the folded leaves the insect, a greenish worm, completely devours the same. By clasping such leaves quickly between your hands the insect 
may be crushed, which is the only means of combating it. The best remedy, as with other pests, is to keep the vines growing vigorously so the foliage thus taken will not be missed. The effect of this insect is seldom, if ever, serious, and is only noticeable when vines are small.

The Steel Blue Beetle is a little hard-shelled bug not much larger than a grain of wheat that in some years is very harmful to the grape, eating off the buds just as they begin to push out in early spring. This insect is very irregular in its work, one year devouring a crop almost entirely and another year being scarcely noticeable. Like the plum curculio, it has the habit of dropping to the ground when the vine is jarred; the way to catch them is to hold a shallow pan partly filled with coal oil, beneath the vire and then give the vine a jar. A tedious job, but sometimes necessary to save the crop.

The Leaf Hopper is an insect which, although not very widely known, has done great injury to vineyards in some parts of the country. It is a leafeating insect and has been known to defoliate vineyards entirely. There is as yet no successful way cf combating it.

\section{BLACK ROT}

Perhaps the most destructive pest of the grape is the blark rot, a fungous disease which usually begins its wcrk after a warm period of rainy weather. It appears first on the leaves, showing itself in brown rust-like spots and blotches, beginning its work on the fruit when the latter is about one-half grown and curtinuing until the fruit ripens, if not all destroyed before that time arrives. A vineyard once infested will remain so ever afterward, providing no steps of prevention are taken, since the spores 
or germs live over winter, becoming worse each year.

Bordeaux mixture is the best known preventive and cure with which every vineyard, whether infested or not, should be sprayed at least once each season. Vineyards where the rot has been at work should be sprayed the first time just as the buds push out and every ten days thereafter, being careful not to spray when the vines are is bloom. The spraying should be thoroughly done; a fine mist-like spray should cover every part of vine and foliage. The disease once thoroughly subdued, the sprayings need not be so frequent the following season, nor is it necessary to spray as often in a dry seasor: as in a wet one.

\section{DOWNY MILDEW.}

This is another fungous disease to which the grape is subject, which acts much in the same way, excepting that it is more injurious to foliage and not so much to the fruit as the rot. Bordeaux mixture is the best remedy.

\section{PHYLLOXERA.}

This so-called disease is caused by the work of a species of small sucking insects. One species of this family (there being several) works on the roots and appear in such great numbers that the roots become one mass of galls and are no longer able to support the vine. Another form works on the leaves, also producing galls, the latter being by far the least injurious. For some years past this pest has done great havoc to the vineyards of France, so that for a time it was feared that the grape, or rather the wine, industry there would have to be abandoned. It is thought that the insect was imported 
from North America. Our native grapes, being more healthy and vigorous than foreign varieties, are more able to resist this and other pests, and while a number of vireyards have been destroyed by this pest, it is not generally known among the vineyards of this country and is by no means the worst enemy to the grape.

The best way to guard against this pest, is in the way of rich soil, liberal feeding, close pruning and thorough cultivation, also by spraying to keep foliage strong and healthy. In this way the vines are kept so vigorous as to be able to resist this and other diseases, as stated previously. When vines that are well cared for in every way show an unaccountable weakness, Phyllexera may be feared and if upon examining the roots they are found to be thus infested, they should at once be dug out and destroyed, lest the disease should spread all over the vineyard.

\section{BIRDS AS A PEST.}

While all will agree that birds in general should be protected, destroying, as they do, vast quantities of insects that are injurious to our fruits, we must in many sections, in order to make grape growing profitable, make the oriole an exception. It is in many cases necessary to keep constant watch and shoot these, one of our most beautiful and sweetest singers. If this bird, like most other birds, would pull off a berry at a time and fly to a nearby tree with it, later to return for another, the injury would amount to comparatively nothing, but not so with the oriole which, being after the juice only, goes from one bunch to another, puncturing enough berries on each to spoil it for market. A single bird thus ruins many a dollar's worth of fruit in the 
course of a day. It may therefore be seen that when they appear in large numbers that the entire crop is destroyed, if not protected.

\section{BAGGING THE GRAPES.}

In small gardens where but a few vines are grown the best means of protecting the fruit is to slip strong paper bags over each and every bunch. One and two pound bags are used, such as are used by grocerymen, etc. The best way to apply these is to tear the opposite corners down say one inch, slip the bag over the bunch and by means of the slits at the corners, let the top of the bag extend beyond the lateral to which the bunch is attached, then by means of fine soft wire or twine, draw the top of the bag tightly. This work should be done as soon as the bunches are well established or when the berries are the size of small peas. The most beneficial result from bagging is the prevention of rot; if the work is thoroughly done, that is, all the good bunches well bagged and the rest pulled off it is a sure cure. Although not necessary for the preservation of the fruit when bagged, it is advisable to give at least one spraying each season to keep the foliage healthy. The bagging generally prevents the birds from injuring the fruit, though an occasional bird is smart enough to tear the bag and destroy the bunches. When fruit is intended for exhibition purposes the bagging is a great advantage, because it preserves the bloom most perfectly. The thought of bagging each and every good bunch, even in a small vineyard, seems like a big task, but when we get at it with nimble fingers a great deal is accomplished in a day. Ore person with a little experience should put on two thousand bags per day, representing two to three thousand pounds of fruit. 
FRUIT-GROIVER CO., ST. JOSEPH, MO. 21

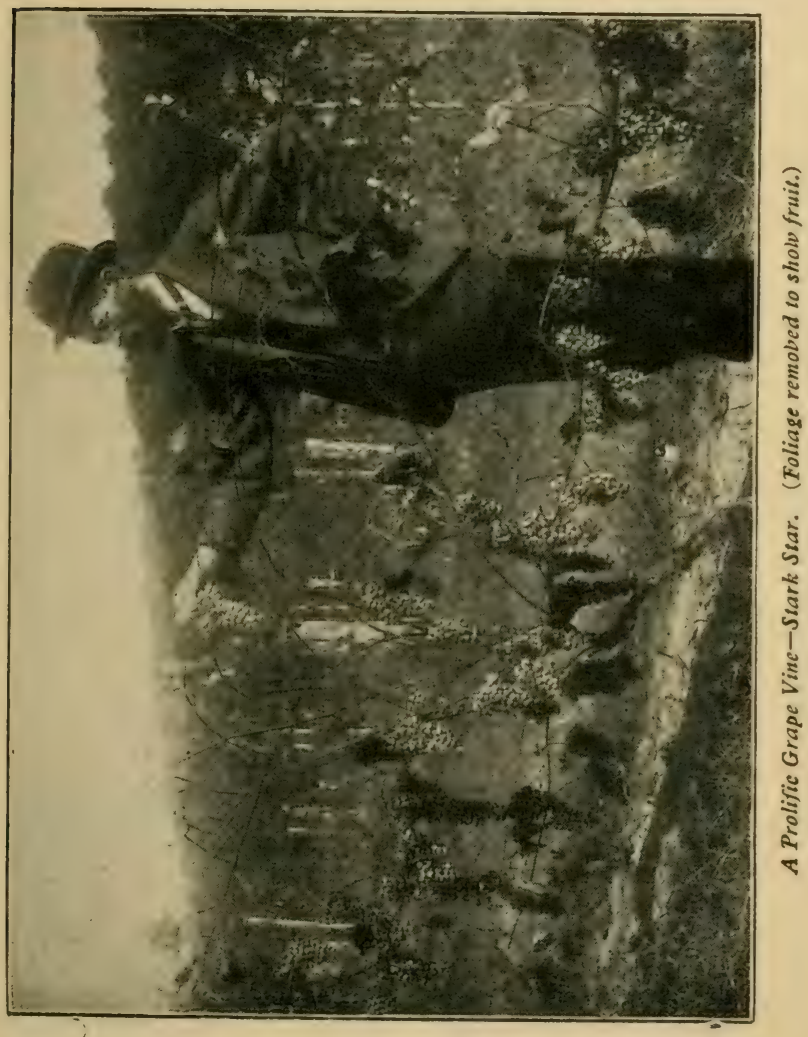




\section{NATIVE VARIETIES.}

It is needless to dwell upon foreign varieties, none of which succeed in our soil and climate. Our first two really good native grapes were Isabella (blacik) and Catawba (red), both of which still remain on our list of profitable grapes; the former has not been held in much esteem since the introduction of the Concord, which is an improvement upon it, but Catawba is still largely grown and sent to market by the tors each season. Catawba is a little weak in foliage, requiring a little closer pruning than most varieties, therefore succeeding with the judicious grower, when under the same conditions the careless grower will fail. These were followed by Diana, Delaware, Rebecca and Concord. Delaware and Concord still remain on our list of profitable varieties. Delaware is a little peculiar in its habits, doing well in one section and poorly in another, yet with special care in the way of high feeding and close pruning it will succeed fairly well anywhere. It is a small red grape of excellent quality.

The best advice to the amateur is: "When in doubt, plant the Concord." It is regarded by the best authorities to be the foundation of our best grapes today and itself is an all-round good variety that succeeds under more adverse conditions than any other. Perhaps more of this variety goes to our markets each season than of all other varieties combined.

Roger's Hybrids are a class of grapes of comparatively recent introduction representing a few varieties that are of value. but all of this class are inclined to be a little weak in foliage, requiring a little special attention in the way of pruning and 
winter protection. Wilder and Herbert, both black, are large in bunch and berry and almost unexcelled when at their best. Goethe is a red belonging to this class, which is perhaps in quality the best native variety in cultivation. This variety should find a place in every home garden, as the grower is more than repaid for the extra attention it requires. Other good varieties of this class are Agawam, Amania, Barry, Gaertner, Lindley, Massasoit and Merrimac, of which there is not space for description.

Woodruff is one of our best red grapes when well grown. It has the fault of overbearing, so that even when closely pruned it is generally necessary to pull off much of the fruit when one-half grown. It is large in bunch and berry, bunch very compact and of excellent quality.

Lutie, a comparatively new variety, is in a red grape what the Concord is in a black, a grape for the masses, succeeding as it does under almost any conditions, as hardy and vigorous as any oak. One of the very earliest to ripen, large compact bunch, very sweet and delicious to most fruit lovers. It has however, quite a little of that peculiar flavor called foxiness, to which some persons object.

Worden, a seedling of Concord, same color, is one-fourth larger, ripens a little earlier and is considerably better in quality. It ripens rather unevenly and has a very delicate skin, which points are against it for shipping; it well deserves a place in the home garden.

The best and most profitable early black grape is Moore's Early. As mentioned in another chapter, it requires a little special attention in the way if pruning, but, all points considered, it is not only the most profitable early grape, but there is not a variety on our entire list that will rival it for profit 
in the vicinity of St. Louis and many other markets. Ripens with the earliest, large in bunch and berry; bunch very compact, black with a handsome blue bloom, quite productive and hardy and so rich and sweet that its hard pulp is not objectionable.

This variety was for a time supposed to have a rival in Campbell's Early, but it has not proven so. Campbell's Early is still larger than Moore's Early, both in bunch and berry and has a tougher skin. Moore's often cracks in wet weather, whereas Campbell's does not; in this respect it is an improvement, but when we consider that it is poorer in quality and not so reliable as a cropper, owing to weaker foliage which renders it less hardy and frequently causes it to ripen unevenly, we will cling to Moore's Early.

In white grapes Green Mountain stands first as an extremely early variety, bunch large, berry small, hardy, productive, quality perfection in a white grape.

Moore's Diamond follows this in ripening; in bunch a little larger, in berry somewhat smaller than Concord; quite productive, quality very good, the skin of the fruit is so tender that in the south it often scorches on the vine; this does not occur further north and as it is very hardy, it is there a success.

If Niagara were a little hardier it would be almost perfection in a white grape. It is, in fact, the ideal grape, though it might represent more wealth to the world at large if it were black. Bunch and berry are uniformly large and perfect, bunch always compact, skin very thin, yet tough enough that it does not crack; very productive and quality very good. It is hardy enough to go through ordinary winters without protection, but north of 45 degrees latitude 
it should in severe winters be laid to the ground. This means to be safe, to do it annually.

Norton's Virginia Seedling and Cynthiana represent our best varieties for heavy red wine and grape juice.

Herbemont (red in color), is a delicious old variety both for table and wine. Still grown in the South, where it succeeds far better than toward the North.

In the way of new grapes we have in the McPike what may be termed a valuable curiosity. It is as much of an improvement over its parent as Worden is over its parent, the Concord. It is the largest excellent grape known. Interesting and valuable in the home garden, but it is feared that for distant shipping it is too large and tender skinned.

Stark Star is beyond a doubt the most wonderful new grape on our list. In productiveness nothing will compare with it. In size of bunch it surpasses all others, berry almost as large as Concord. Perfection in vigor and hardiness, dark red in color almost black, skin thin but tough, therefore one of the best shippers; quality fair when fully matured. It requires a long season to ripen, therefore may prove of greater value in the south than toward the north, where it should be planted only in an experimental way. Vigor and hardiness in Stark Star was obtained from the wild grapes of our forests, size and quality from our best cultivated sorts, it being a result of a cross between the two. The originator of the above grape, Joseph Bachman of Arkansas, no doubt got his idea of such a cross from T. V. Munson of Texas, who is regarded today as the best authority on the grape the world has ever seen. Mr. Munson has originated hundreds of varieties by such crossing, many of which are on our list of good grapes 
and planted extensively in the south, but they are as yet but little known toward the north.

\section{PROPAGATION.}

The grape is usually propagated from cuttings, varying in length from eight to eighteen inches. When joints are long sometimes but two buds are used to a cutting, one at each end, a keen cut being made just below the lower and above the upper bud. It is better to have cuttings coritain three or more buds, which can be given when wood is short jointed. The cuttings should be made in the fall when wood is thoroughly dormant, preferably before severe freezing weather, tied in bundles and packed in moist sawdust or sand in the root cellar or buried in the ground in a sheltered place outside. They should be lined out in the nursery as early in spring as the ground is dry enough to work well; the earlier the better, for if deferred the buds may push forth and many of them be knocked off in handling.

The soil should be worked to the full depth of the cuttings, made fine and firm with drag or roller. A furrow is then made with the spade the depth of the cutting, with a straight bank on one side. Place cuttings along this bank four to six inches apart, push the mellow earth to them, tramp firmly and level up so the top bud is level with the surface. Some authorities advise setting the cuttings at a slope of forty-five degrees, but the writer thinks best to put them perpendicular.

Cuttings are also made of single eyes or budis, which is done to hasten propagation when varieties are new and the wood scarce. The wood is cut up into lengths containing one bud each and these are placed flat on sand in pots or on benches in a green 
house or in a hot-bed; an inch of sand is then put over them; uniform bottom heat is necessary for them to succeed. These single-eye cuttings make weak vines and should be avoided if others are to be had.

Some varieties do not grow well from cuttings and must be grown by layering or grafting. Layers are usually made of young wood of the previous year's growth. Select a bud on a young cane about one foot from the root of the vine, place a sharp knife just below the bud and cut upward under and slightly past the bud; now withdraw the knife, give the vine a gentle twist and at the same time turn it upward, causing the lip containing bud to turn downward, push this knee, as it were, down into an opening in the ground made for it to the depth of two or three inches, and secure it there by firmly pressing fine, moist earth about and over it; if necessary pin it down with one or two sharpened sticks or a forked stick. The vine may be curved and put down again in the same way, sometimes making two, three or more vines of one cane. Layers will generally root by simply bruising and twisting the vine where it goes into the ground, but the lip method is surer and makes better vines. Layers may also be grown from green wood of the present season's growth.

In grafting the grape, the cleft graft is used the same as for grafting fruit trees, etc. Time to graft is when the sap begins to move in the stock, the scion to be dormant. Great gains are to be realized by grafting the grape. Unprofitable vineyards may in one year's time be turned into profit producing any desired variety or varieties, or one year sld vines in the nursery may be changed to some rare new sort, the single bud inserted into each vine get- 
ting the benefit of the vigorous young root and in one season make a splendid vine for the vineyard. The grafting is done from one to four inches below ground at which point the vine to be grafted is to be cut or sawed off; if stock is large it must be split by sawing down through the center of the stump; now drive a hard narrow, wooden wedge into the center of this cut, trim the edges of the openings on either side and on each side, carefully fit a scion, containing from one to three buds. Care should be taken to see that the inner barks of stock and scion come exactly in contact with each other and we should understand that the bark of scion being much thinner than that of stock, the scion must be set in a little way in order to have the inner barks together. The scions rightly placed, the wedge is carefully withdrawn, which pinches the scions firmly and makes tying unnecessary.

Moist, mellow earth is then packed firmly around the base of scions, fine earth is then banked up to the top of scion, leaving a flat surface on top on which is placed from four to six inches of sawdust. The graft is then left unmolested until growth appears, which may be in from two to eight weeks, when growth appears there should be an examination to determine whether it comes from the scion or from the root below. Suckers from the old root should of course be promptly removed. When small stocks are grafted the splitting is done with a sharp knife and the scion firmly bound in place with stroing twine.

The greatest drawback about grafting the grape is that it is expensive work for the beginner, especially if the vines sacrificed for another variety are of value, because almost every root upon which the grafts fail is lost. The writer got his first experi- 
ence by grafting wild vines, which resulted in fine large grapes being found growing in the woods, the fence row and other waste places about his home. Perhaps others may profit by this suggestion.

\section{GATHERING AND MARKETING.}

Perhaps the most important point to consider in gathering grapes for market is that the fruit must be thoroughly ripe when taken from the vine, as, unlike most other fruits, it does not ripen after being gathered. With several varieties, more than color is necessary for the fruit to be marketable, as they color before they are ripe. Take for example the Ives, which is one of those that color prematurely. Some years ago tons of this variety were sent to our northern markets when fairly colored, yet the fruit was sour and unfit to eat. The result was that the consumer condemned early grapes and the market for the same was ruined for some years to follow. Now that we have Moore's Early and Campbell's Early and the southern growers are the wiser for an expensive lesson, early grapes are in demand and in most sections more profitable than the later sorts.

In gathering grapes a firm, shallow basket or tray should be used. The one-third bushel melon basket makes a good package for this purpose. Care should be taken to handle the bunches as much as practicable by the stems in order to preserve the bloom on the fruit as much as possible. The fruit should be taken to cool in a spacious shed, which shed should preferably be shaded by large trees during the worst heat of the day. It is generally preferable to have the fruit gathered a few hours before it is packed, as during this time the bunches shrink a 
little, which makes the handling easier. Women and girls are usually employed to clip out the injured and imperfect berries and pack into the shipping baskets. Care should be taken to have the fruit grade well all through the package and it is a wise plan for each shipper to consign all of his fruit to ore firm, that he has reason to believe is reliable. This will enable the merchant and his customers to get acquainted with your fruit and the label, or trade mark, which every basket should bear, will be looked for. The grower who sends poor or carelessly packed fruit to market is not only loser himself, but it is just such work that breaks down the markets. Many a person has decided not to purchase a second basket of fruit because the last one, which looked so nice on top, was more disappointing than anything else.

The Climax basket is the package most generally used for the grape, of which there are several sizes holding from five pounds up, the different sizes meeting the requirements of different markets. Fruit should always be well cooled before it is started on its jourrey to market. For the home market the four-basket crate is frequently a desirable package. When fruit grades well in the vineyard it is a good plan to pack the fruit from the vine to package, thus saving time and preserving the bloom; a few imperfect berries may be picked off, as the home market is not critical so long as fruit is good and shows up well.

Most growers have not the nerve to pull off the small and straggling bunches early, to throw more vigor into the marketable bunches and have less to handle, and others think they have not time to do it. If this is not done, a lot of culls are on hand to be made some use of. Those who understand the prin- 
ciples of wine making and are equipped for it, can utilize this waste to a good advantage, but otherwise it should not be undertaken, as the result will prove worse than worthless.

Many professional wine makers are so eager for quantity that to avoid waste they cut the grapes before they are ripe enough to make a good wholesome wine. They do not seem to understand that to defer the cutting a few weeks and get but onehalf the quantity would give a greater profit, owing to superior quality.

Unfermented grape juice and jelly is doubtless the best way to use up the culls.

Fruit-growing will never be what it should be until the culls are done away with and only good fruit is produced, which is by no means impossible. One of the first and best steps to take in this direction is for growers not to undertake more than they can properly handle. There are scores of instances where if the grower had but one-half the area in fruit that he now has, then having all he could properly attend to, he would realize more profit, have less worry and others would share the benefit. 


\section{THE MUNSON SYSTEM OF TRAINING GRAPES.}

In connection with the matter on subject of grape culture presented in this booklet, it is desired to present some information concerning a form of grape trellis which is advocated by Mr. T. V. Munson, of Denison, Texas, one of the best authorities on the grape in the world. Mr. Munson describes his trellis as follows:

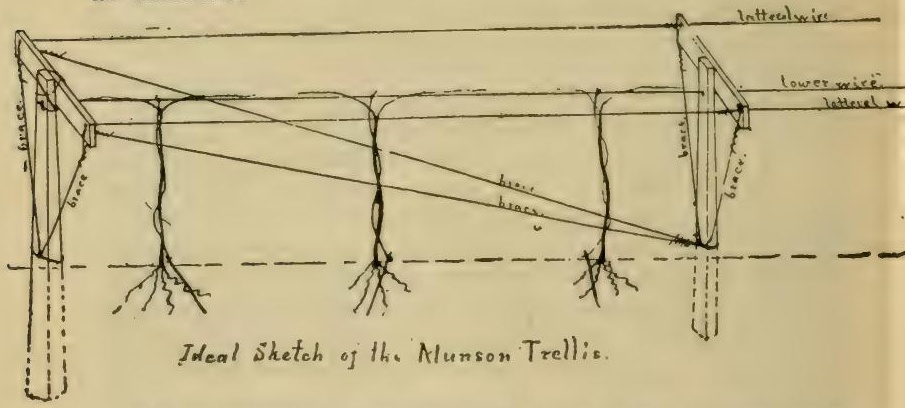

"The essential features of the trellis consist of three horizontal parallel wires, supported above and along each row of vines by any system of permanent posts and arms most available to the planter.

"The middle, or lower, wire should be some four or five inches lower than and midway between the two upper wires, which should be about twenty or twenty-two inches apart, and four and a half or five feet from the ground, or they can be as low as three feet from the ground in dry, windy climates.

"No. 11 galvanized wire is sufficiently strong for the wires, and experience has shown that twenty- 
four feet between the posts is the right distance. The end posts should be strong and set not less than three feet deep: four feet is still better, thus avoiding the necessity of bracing them. The intermediate posts need not be set over two feet in the ground, as they merely sustain the downward pressure of the vines, the end posts taking up all of the lateral strain.

"Sketch on opposite page shows a view of the end post of this trellis, together with the post next to it, with young vines being trained up to the lower wire, along twine strings tied to stakes at the root, and to the middle wire at the top. In actual practice the two lateral, or side wires are not put on until the winter of the second year, after the young vines have been pruned and tied as in Figure 2.

"While it is stated that the end posts are not braced, where set deep in the ground, it will be noted from the sketch that the cross-arms are braced. The ones attached to the end posts are braced by the longer wires marked 'brace' attached to the next post, to prevent the arms from being pulled back and forth by the lateral wires. Each cross-arm is also braced by the shorter brace wires, attached to the same post, so that if the load on one wire is heavier than that on the other, one side will not be drawn down and the other side raised. These brace wires are simply to make the lateral wires stable, by bracing the cross-arms.

"In using this trellis the vines are planted immediately beneath the middle wire. The first season the growth is restricted to one vigorous shoot, which is trained about a string, as shown in the illustration. This string is simply to get the growing shoot up to the middle wire, and of course has no part in 
the permanent trellis. By restricting the growth to this one shoot, a vigorous growth can be obtained, and this forms the main trunk of the vine in after years.

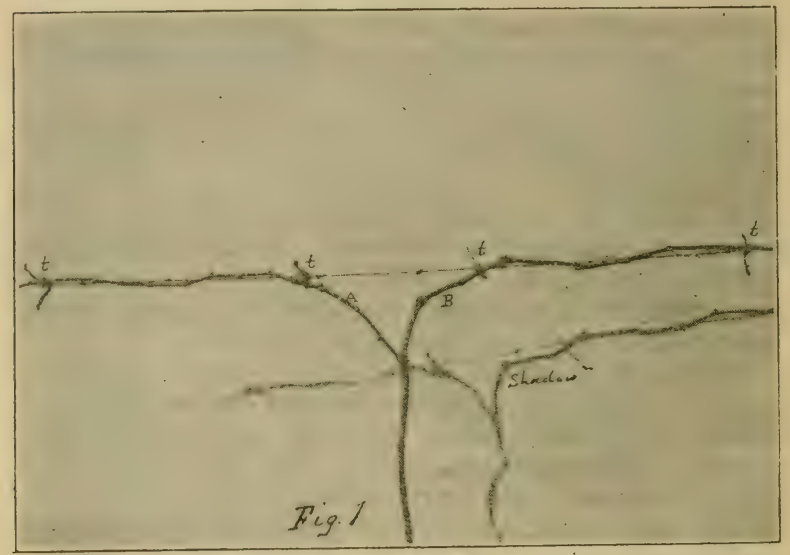

"Figure 1 shows a vine after having made one year's strong growth, pruned and tied. The vine has two branches, $A$ and $B$, each tied at $t \mathrm{t}$, and the trellis is now ready to have the cross-arms and two lateral wires put on.

"In this system little tying of the vines is needed; the first year, as shown in Figure 1, two canes are left, and each is tied near its base, and is then wrapped about the middle wire, and tied again at the extreme end. As the vine becomes older, two more canes are left, one running each way, but never more 
than four canes are left to bear. These canes are tied to the middle wire, always, and the new growth, the bearing shoots, extend over the side wires, and attach themselves thereto by their tendrils. The fruit is thus borne under a canopy of green leaves, with free circulation of air underneath.

"This system of training contemplates the renewing of the vire, from the main trunk, every year. Accordingly, an effort is made to grow canes starting from near the head of the trunk every year, to replace the old ones, which are entirely pruned away. Take, for instance, a vine which has four canes left to bear fruit. When growth begins in spring, select fcur new shoots which will come out rear the head, and leave them to produce the bearing wood for the next season's crop. All other shoots which start must be rubbed off, and of course no new growth should ever be allowed on the main trunk, beneath the head. By keeping off all other shoots which start, the growth of the plant will be thrown into those which are left for the next season, and in the shoots which are then bearing a crop of fruit.

"Figure 2 shows a vine after having borne its sixth crop of some forty pounds of fine fruit each year, after the leaves have fallen, and the vine is ready for pruning. From $A$ to $T$ and from $B$ to $T$ are shown the four last-year arms, two going in each direction, gently twined along the lower wire, one arm being twined around the wire in one direction and the other in the opposite direction, thus holding each other in place on the wire, and requiring only one tie for each pair of arms-near their ends, at T $\mathrm{T}$.

"This illustration was made from a photograph of a vine of the Ben Hur variety, occupying a space of 
fully fourteen feet on the trellis, all of which space was filled with clusters borne on shoots coming out of the arms and extending up over the lateral wires, the extremities, when in full leaf, hanging over the

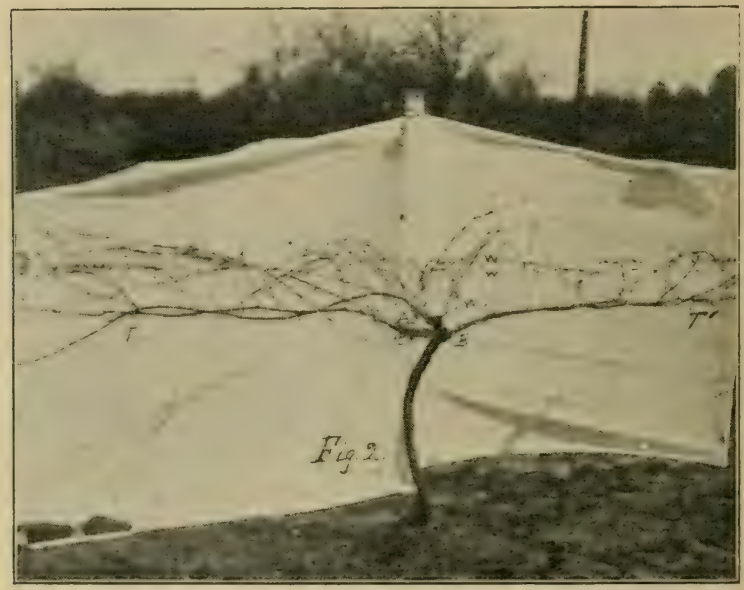

wire like a most beautiful drapery, on each side of the trellis. This constitutes the trough-shaped canopy of foliage over the pendulous fruit below, producing a most beautiful sight and the finest possible fruit, placed in the best possible position for cultivation, for pruning, spraying, harvesting, ventilation, and for allowing one to pass from one row to another.

"Figure 3 shows this same vine pruned, ready to be tied, with all the cut-away wood removed from the trellis. Note that the old arms are entirely cut 
away, back to where the new arms come out, and only wood of last summer's growth, coming out from the head of the vine, is chosen from among the most vigorous shoots pushed out near the crotch of the vine, and which should not have been allowed to

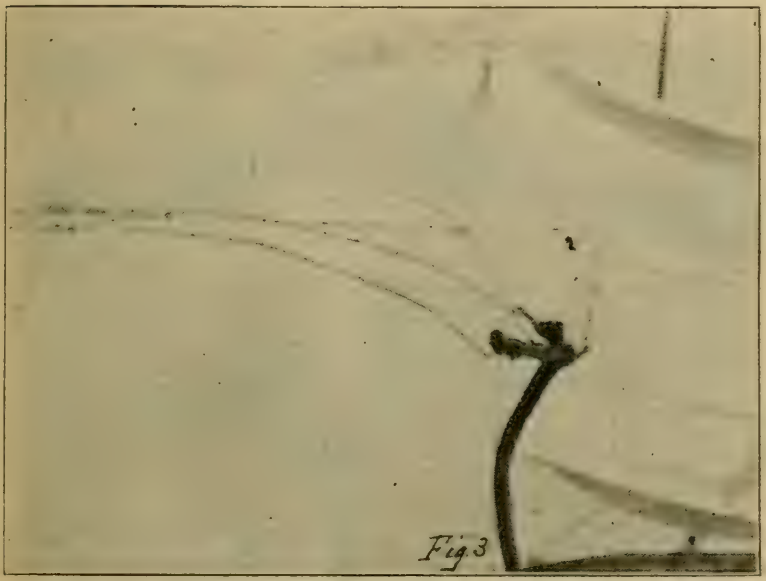

bear any fruit during their first season. This is strictly the renewal system, in contradistinction to the spur system.

"Figure 4 shows the same vine tied with two ties, $t$, ready to do the work of next growing season. "After the first crop, when only two short arms are retained in pruning, if the vines are in good vigor, four arms are retained for the second crop, two arms to go each way, and each year thereafter the length of the arms left is determined by the vigor of the 
vine. If the vine has perfected its crop well and made an excess of new wood over the previous year, leave the arms longer proportionately. But if the vine seems over-worked, and has made less new wood than it did the previous year, then shorten the arms proportionately.

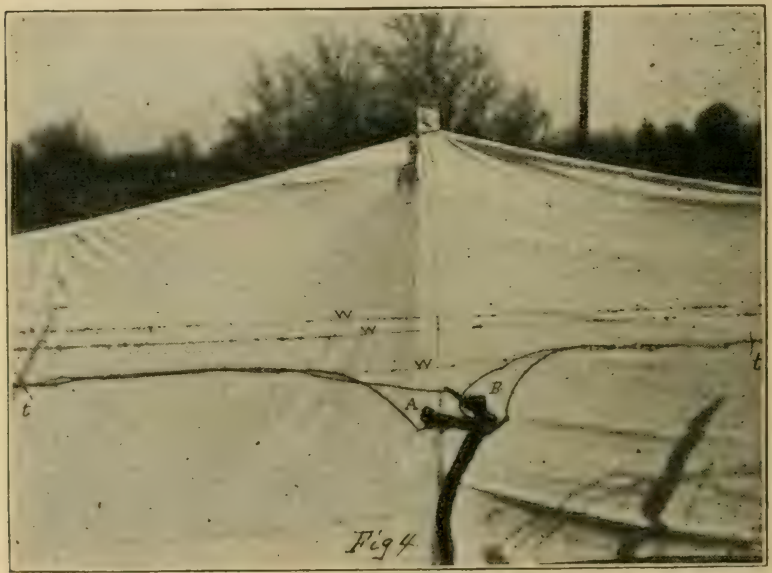

"The advantages of this system are many. In the first place, the work of pruning and tying the vines is reduced to the minimum. In pruning, the arms which have borne the fruit are cut away entirely, and their places taken by the other canes which have been left for this purpose. In tying these canes, they are wrapped about the middle wire, and only one tie is needed for the two arms going in one direction (see Fig. 4). Cultivation is facilitated because of the 
fact that the mass of foliage is well above the ground. The fruit is not so likely to rot, for the bunches are borne well above the ground, and as the mass of foliage is horizontal, between the lateral wires, instead of vertical, as in the case of the oldfashioned trellis, the air has free circulation beneath the vines, thus reducing the danger from rot to the minimum. And if it is necessary to spray the vines, the work can be more easily done. With one hand the operator can hold up the drooping foliage and with the other direct the spray mixture under the canopy to the fruit. Then, too, one can pass readily from one row to another, whereas with the old vertical trellis one might be compelled to go to the end of a long row to get into another part of the vineyard. In cold climates. where it is necessary to lay vines down and cover during the winter, this form of trellis will be found particularly valuable. The vines can be pruned as soon as leaves are off in the fall, and the whole plant can then be laid down and covered up, with very little trouble. Next spring the vine can be lifted and the arms tied as recommended, and the plants are ready to bear a crop."

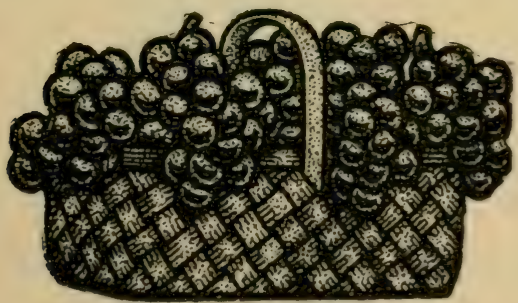


MAY 49906

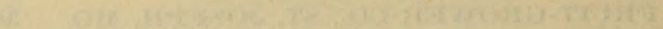

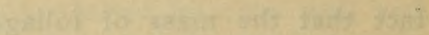

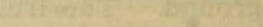

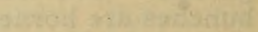

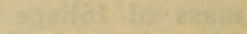

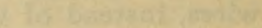

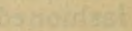

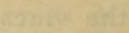

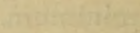

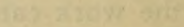
t.

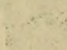




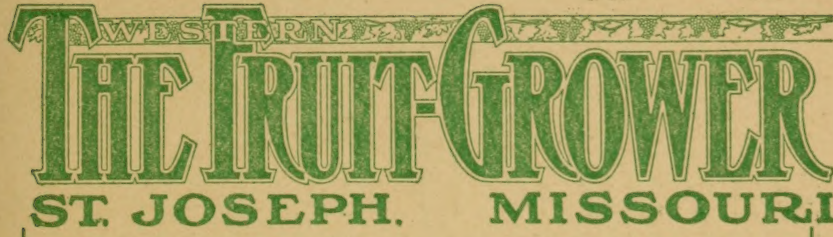

\section{America's Leading Horticultural Paper}

Published Monthly - Send For a Free Sample Copy

\section{One Dollar a Year=Three Years $\$ 2$}

One "Brother Jonathan" Book Free with every remittance of $\$ 1.00$ on subscription

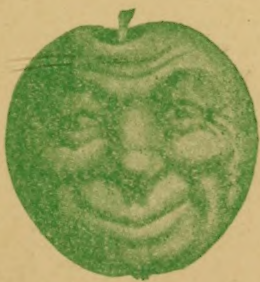

"Brother Jonathan"

Trade Mark of The Fruit=Grower

St. Joseph, Mo. 
The Fruit $=$ Grower Company can furnish, at nominal prices, books covering almost every -subject in connection with fruit-growing and general farming. If you are inter. ested, send at once for our book list, which will tell you how to secure "The Bro. Jonathan Series" complete, or any other books on our list, without cost to you. If you have not seen a copy of The Fruit-Grower, send for a sample, which will be sent free. If you will send names of a few of your friends who grow fruit, we will appreciate it. Address all correspondence to

The FRUIT=GROWER COMPANY ST. JOSEPH, MISSOURI 


\section{LIBRARY OF CONGRESS}

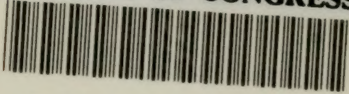

\section{4}

